\title{
Experiences with the Sitting Position in Posterior Fossa Surgery in 310 Patients
}

\author{
Heymanns V'\#, Jung $\mathrm{S}^{2 \#}$, Tallo $\mathrm{A}^{2}$, Cheko $\mathrm{A}^{2}$, Alyeldien $\mathrm{A}^{2}$, Tsogkas $\mathrm{A}^{2}$, Doukas $\mathrm{A}^{3}$, Daemi-Attaran $\mathrm{P}^{2}, \mathrm{Alsharif}^{2}{ }^{2}$, Mahvash $\mathrm{M}^{4}$, Scholz $\mathbf{M}^{2}$ and \\ Petridis $\mathrm{AK}^{2,5 *}$ \\ ${ }^{1}$ Department of Pediatrics, Sana Kliniken Duisburg, Germany \\ ${ }^{2}$ Department of Neurosurgery, Sana Kliniken Duisburg, Germany \\ ${ }^{3}$ Department of Neurosurgery, University Schleswig Holstein, Campus Kiel, Germany \\ ${ }^{4}$ Department of Neurosurgery, Helios Klinikum Siegburg, Germany \\ ${ }^{5}$ Department of Neurosurgery, University Hospital Duesseldorf, Moorenstr, 540225 Duesseldorf, Germany \\ \#Verena Heymanns and Suzin Jung contributed equally
}

\begin{abstract}
Introduction: The sitting position for lesions in the posterior fossa has been controversially discussed in the literature because of high risk of air embolism. We report our experience with the sitting position and evaluate the risk of air embolism

Material and Methods: We performed a retrospective analysis of patient charts $(\mathrm{N}=310)$, surgical and anesthesiological reports to evaluate the occurrence of intraoperative complications. Pre and post-operative MRIs were also evaluated for occurrence of embolic infarctions. The patients were operated in our department from 2009-2013.

Results: Only $0.6 \%$ of patients suffered from embolic infarctions. Most of the complications were similar to the complications which occur in the lateral oblique position. Preoperatively, all patients were evaluated with echocardiography to exclude a patent foramen ovale (those patients were not operated in the sitting position).

Conclusion: The sitting position is excellent for surgery in the posterior fossa since blood is washed out and does not intervene with the surgical field. The risk of air embolism is very low when a patent foramen ovale has been excluded. Intraoperatively, a right ventricular catheter is inserted to aspirate air if needed. Meticulous coagulation, irrigation of the surgical domane and application of bone wax to the craniotomy edges reduces the risk of venous air embolism.
\end{abstract}

Keywords: Sitting position; Posterior fossa; Air embolism

\section{Introduction}

The use of sitting position for patients undergoing posterior fossa and cervical spine surgery, facilitates excellent surgical access, but presents unique physiological challenges with the potential for serious complications, such as hemodynamic instability, Venus Air Embolism (VAE), pneumoencephalus, quadriplegia and compressive periferal neuropathy $[1,2]$. Alternative positions for the posterior fossa and cervical spine surgery include the prone and lateral position. Prolongated neurosurgical procedure with pin fixation of the head in an abnormal position necessitates extensive patient monitoring to insure cardiorespiratory stability. The lateral oblique position decreases the risk of VAE compared to the sitting position. Although the sitting postion is thought to provide important advantages, the risk of air embolism led to abandon it in a number of neurosurgical departments. The sitting position is nevertheless still considered from many neurosurgeons to be a well tolerated patient position, if a strict team protocoll is followed (neuroanethestic and neurosurgical). Since the use of the sitting position remains controversial, we present a study reporting our experience and the complication rate we observed.

\section{Material and Methods}

Three hundred and ten $(\mathrm{N}=310)$ patient charts treated in our hospital in the years 2009-2013 for posterior fossa pathologies were retrospectively evaluated. We operated all patients in the sitting position after exclusion of a persistent foramen ovale. Regular intravenous anesthesia with right ventricular Doppler echocardiography was always performed intraoperatively. We focused our interest on complications concerning the sitting position i.e. air embolic infarctions. We also discuss advantages and disadvantages of the sitting position and compare the complication rates of our patients with historical controls in the literature.

\section{Results}

Figure 1 illustrates the different pathologies we operated on in the sitting position. In close cooperation with the anesthesiologist, patients

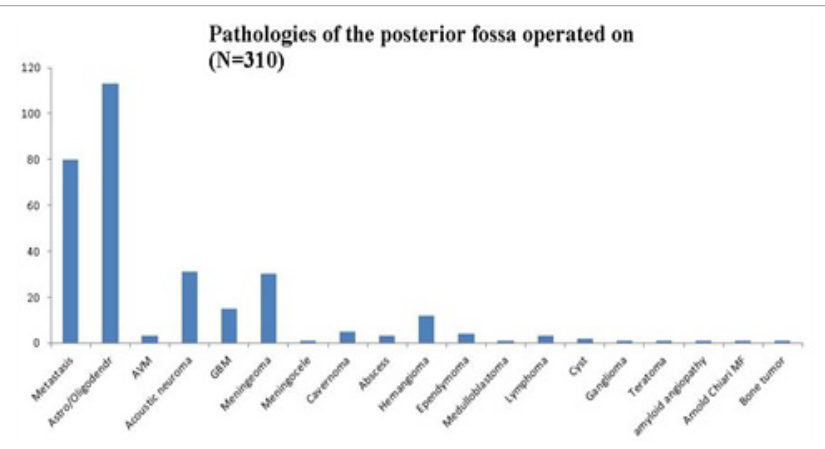

Figure 1: Posterior fossa pathologies on $\mathrm{N}=310$ patients operated on the posterior fossa in our department from 2009 to 2013.

*Corresponding author: Athanasios K. Petridis, Department of Neurosurgery University Hospital Duesseldorf, Moorenstr, 540225 Duesseldorf, Germany, Tel: 492118107439, Fax: 492118104514, E-mail: opticdisc@aol.com

Received August 28, 2015; Accepted October 17, 2015; Published October 20, 2015

Citation: Heymanns V, Jung S, Tallo A, Cheko A, Alyeldien A, et al. (2015) Experiences with the Sitting Position in Posterior Fossa Surgery in 310 Patients. J Neurol Disord S1: 002. doi:10.4172/2329-6895.S1-002

Copyright: @ 2015 Heymanns V, et al.. This is an open-access article distributed under the terms of the Creative Commons Attribution License, which permits unrestricted use, distribution, and reproduction in any medium, provided the original author and source are credited. 


\section{Sitting position complications}

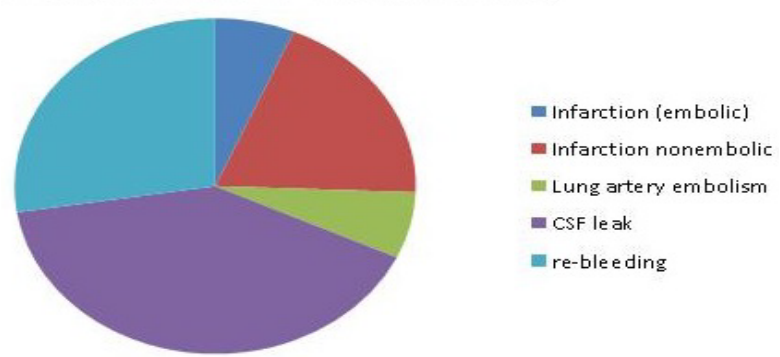

Figure 2: Distribution of complications in patients operated on the sitting position. The most common complication we encountered was CSF leakage. Embolic infarction and lung artery embolism were less common.

were intraoperatively monitored for venous air emboli with a right ventricular doppler ultrasonography. When air was aspirated through the veins, the anesthesiologist informed the surgeon immediately and all the surgical layers were thoroughly inspected. From the beginning of the surgery we perform meticulous coagulation of bleeding vessels. In case air is aspirated, the anesthesiologist increases the PEEP to 15 $\mathrm{cm} \mathrm{H}_{2} \mathrm{O}$ and we irrigate the wound with normal saline, inspect and coagulate possible open veins. The bone edges after craniotomy are covered with bone wax and fibrin glue.

A very small percentage of the complications we identified were embolic infarctions of the lung and further of the brain (Figure 2). None of the patients with embolic infarctions had a neurologic disability caused by this complication. Notably, although there were cases of air aspiration through the veins intraopreatively (15\%) only in $0.6 \%$ the anesthesiologist had to remove a significant amount of air from the right ventricle. In $0.6 \%$ of the patients an embolic brain infarction did occur. In none of these patients did the anesthesiologist aspirate air and there was $0 \%$ mortality or neurologic deficit because of this complication. The reason why patients had indeed a cerebral embolic infarction could not be exactly found. $1.8 \%$ of patients had a nonembolic infarction, which was caused by direct coagulation of a vessel in the posterior fossa during surgery and cannot be attributed to the sitting position, $0.6 \%$ suffered of lung artery embolism, $3.8 \%$ of CSF leak and $2.58 \%$ had a re-bleeding.

\section{Discussion}

One important pioneer in neurosurgery and, in particular, posterior fossa surgery was the British surgeon - Sir Victor Alexander Haden Horsley. Horsley performed a significant number of posterior fossa surgeries in the lateral oblique position, the technique of which he described in 1906 [3].

Surgery of the posterior fossa became more and more popular the following decades and further innovations in posterior fossa surgery were developed, amongst others by Thierry de Martel. De Martel was an early pioneer in the use of the sitting position for posterior fossa and cerebellopontine angle surgery [4,5]. He designed his own surgical chair with various positioning devices to correctly position the patient [4]. He suggested the sitting position for neurosurgical procedures in 1931 [6] and ever since, arguments and debates about pros and cons of the sitting position for surgical procedures involving the posterior fossa, and craniocervical junction, continue.

Besides common perioperative risks of neurosurgical operations, the specific risks of the sitting position are venous air embolism (VAE) and, more importantly, the fatal paradoxical air embolism (PAE) due to a patent foramen ovale (PFO) [7]. Additional risks of the sitting position could be haemodynamic instability, pneumocephalus, quadriplegia, macroglossia, and compressive peripheral neuropathy $[2,8,9]$.

On the other hand, this patient position has a lot of advantages. It offers optimum anatomical orientation and exposure, excellent access to midline lesions, lowers intracranial pressure and accumulated blood drains out of the operation field. It can also potentially decrease transfusions requirements [10].

Retractions of the cerebellum in supracerebellar, infratentorial approaches can be minimized and furthermore responses of cranial nerve stimulation during manipulation can be observed through the open view of the face [11].

From the anesthesiologist's point of view, it offers improved access to the tracheal tube, chest wall and arms [12-15].

Given the many advantages but also risks of the sitting position, it seems comprehensible to discuss and evaluate the best patient position for each operation. While in the 1960s and 1970s sitting position surgery was at its peak, there are a lot of studies which show decreasing use of this positioning $[10,16,17]$.

The sitting position requires a thoroughly anesthesiological preoperative evaluation and diagnostics in order to decide whether to use this positioning for posterior fossa or spine surgery or not. A PFO is the major reason for cerebral arterial air embolism [18-24]. Therefore a patent foramen ovale is an absolute contraindication for the sitting position. Its prevalence in normal population varies from $25 \%$ up to more than $40 \%$ [7] and therefore it is absolutely necessary to exclude a PFO before surgery in sitting position is performed. Transesophageal Echocardiography (TOE) or precordial Doppler is the gold standard to establish the diagnosis.

Through the elevated positioning of the head, the venous pressure at the surgical level is usually negative and when there are open venous vessels, air can enter.

Fathi et al. showed that the overall rate of VAE during neurosurgery in sitting position was 39\% for posterior fossa surgery and $12 \%$ for spine surgery [25]. The incidence ranged from 25\% [1] up to 50\% [26] as documented through precordial Doppler. Through transesophageal echocardiography VAE was detected in up to $76 \%$ of the cases [23]. The review of the literature from 1976 to 1994 of the rate of VAE between sitting and horizontal position showed an incidence of $28,4 \%$ in the sitting and 5,5\% in the horizontal position $[1,10,14,15,26]$. Dilmen et al. [8] described 20,4\% of VAE rate in adults in his analysis.

Not every VAE results in the more dangerous and fatal paradoxical air embolism. Clinical and through transesophageal echocardiography registered PAE were found in $0-14 \%$ of the cases [23,27-29].

The morbidity and mortality of VAE are highly correlated to the volume and rate of air accumulation [22]. The volume that reaches the arterial circulation is crucial for the clinical consequences [28]. There are in fact studies that show VAE in the sitting position even without PFO. Therefore, the volume and frequency of air entering the venous circulation should be minimized as much as possible right from the beginning of the operation [22,24]. Muscle preparation, craniotomy, the use of nitrous oxide, and the use of PEEP over $5 \mathrm{~cm} \mathrm{H}_{2} \mathrm{O}$ raise the risk of VAE $[1,30,31]$. The therapeutic maneuvers on the part of the anesthesiologist include: $100 \% \mathrm{O}_{2}$, ceasing $\mathrm{N}_{2} \mathrm{O}$ administration, bilateral jugular venous compression, lowering the head if possible, intravenous fluids to increase venous pressure and aspiration of air from a right atrial catheter [20]. 
Citation: Heymanns V, Jung S, Tallo A, Cheko A, Alyeldien A, et al. (2015) Experiences with the Sitting Position in Posterior Fossa Surgery in 310 Patients. J Neurol Disord S1: 002. doi:10.4172/2329-6895.S1-002

In our study we observed a very low risk of embolic infarctions to the lung. We had some insignificant amounts of air aspiration intraoperatively but immediate response with identifying of the opened vein and meticulous irrigating throughout the whole surgery decreased the risk of complications caused by air in the venous system. Compared to studies in the literature, the rate of VAE and PAE in our study remained very low.

There are studies which show better neurological outcome and less blood loss after operating in the sitting position $[1,2,10,14,15]$. On the other hand, Spektor et al. found no significant advantages of the sitting position versus the lateral position in regards to the clinical outcome of the patients [32]. Bleeding from venous vessels should be coagulated right from the beginning of the operation and also during muscle preparation and craniotomy. Bone waxing of the edges of the craniotomy should be used at all times as well as meticulous irrigation of the surgical field. The use of nitrous oxide and adjustment of the PEEP should be applied carefully.

\section{Conclusion}

In summary, we do not think that the sitting position exposes the patient to additional risks. The risk of embolic lung infarction, which is anticipated using the sitting position was not as high as we would expect. A clean surgical field and a very low rate of additional complications turn the sitting position to our favorite one. The decision for or against it, depends also on the preference of the surgeon, the additional medical conditions of the patient and the pathology which has to be operated and should always be individualized.

\section{References}

1. Slbin MS, Babinski M, Maroon JC, Jannetta PJ (1976) Anesthetic management of posterior fossa surgery in the sitting position. Acta Anaesthesiol Scand 20: 117-128.

2. Lindroos AC, Niiya T, Randell T, Romani R, Hernesniemi J, et al. (2010) Sitting position for removal of pineal region lesions: the Helsinki experience. World Neurosurg 74: 505-513.

3. Papadopoulos G, Kuhly P, Brock M, Rudolph KH, Link J, et al. (1994) Venous and paradoxical air embolism in the sitting position. A prospective study with transoesophageal echocardiography. Acta Neurochir (Wien) 126: 140-143.

4. Figueredo-Gaspari E, Fredes-Kubrak R, Canosa-Ruiz L (1997) Macroglossia after surgery of the posterior fossa. Rev Esp Anestesiol Reanim 44: 157-158.

5. Anzola GP, Zavarize P, Morandi E, Rozzini L, Parrinello G (2003) Transcranial Doppler and risk of recurrence in patients with stroke and patent foramen ovale. Eur J Neurol 10: 129-135

6. Barlow J (1831) An Account of the Removal of a Tumour situated on the Cheek. Med Chir Trans 16: 19-35.

7. Fathi AR, Eshtehardi P, Meier B (2009) Patent foramen ovale and neurosurgery in sitting position: a systematic review. Br J Anaesth 102: 588-596.

8. Duke DA, Lynch JJ, Harner SG, Faust RJ, Ebersold MJ (1998) Venous air embolism in sitting and supine patients undergoing vestibular schwannoma resection. Neurosurgery 42: 1282-1286.

9. Heckmann JG, Lang CJ, Kindler K, Huk W, Erbguth FJ, et al. (2000) Neurologic manifestations of cerebral air embolism as a complication of central venous catheterization. Crit Care Med 28: 1621-1625.

10. De Martel T (1908) Un point de technique opératoire dans la craniectomie. Presse Med 16: 641-643.

11. Bithal PK, Pandia MP, Dash HH, Chouhan RS, Mohanty B, et al. (2004) Comparative incidence of venous air embolism and associated hypotension in adults and children operated for neurosurgery in the sitting position. Eur $\mathrm{J}$ Anaesthesiol 21: 517-522.

12. Horsley $\mathrm{V}(1996)$ On the techniques of surgeries of the central nervous system. BMJ 2: 411-423
13. Chatelin $\mathrm{CH}$, de Martel $\mathrm{T}$ (1918) Wounds of the skull and brain. University of London Press, London

14. Elton RJ, Howell RS (1994) The sitting position in neurosurgical anaesthesia: a survey of British practice in 1991. Br J Anaesth 73: 247-248.

15. Spektor S, Fraifeld S, Margolin E, Saseedharan S, Eimerl D4, et al. (2015) Comparison of outcomes following complex posterior fossa surgery performed in the sitting versus lateral position. J Clin Neurosci 22: 705-712.

16. Dilmen OK, Akcil EF, Tureci E, Tunali Y, Bahar M, et al. (2011) Neurosurgery in the sitting position: retrospective analysis of 692 adult and pediatric cases. Turk Neurosurg 21: 634-640.

17. Domaingue CM1 (2005) Anaesthesia for neurosurgery in the sitting position: a practical approach. Anaesth Intensive Care 33: 323-331.

18. Rath GP, Bithal PK, Chaturvedi A, Dash HH (2007) Complications related to positioning in posterior fossa craniectomy. J Clin Neurosci 14: 520-525.

19. Campkin TV (1981) Posture and ventilation during posterior fossa and cervical operations. Current practice in the United Kingdom. Br J Anaesth 53: 881-884.

20. Mirski MA, Lele AV, Fitzsimmons L, Toung TJ (2007) Diagnosis and treatment of vascular air embolism. Anesthesiology 106: 164-177.

21. Pham Dang C, Péréon Y, Champin P, Delécrin J, Passuti N (2002) Paradoxical air embolism from patent foramen ovale in scoliosis surgery. Spine (Phila Pa 1976) 27:E291-295.

22. Cucchiara RF, Nugent M, Seward JB, Messick JM (1984) Air embolism in upright neurosurgical patients: detection and localization by two-dimensional transesophageal echocardiography. Anesthesiology 60: 353-5.

23. Mammoto T, Hayashi Y, Ohnishi Y, Kuro M (1998) Incidence of venous and paradoxical air embolism in neurosurgical patients in the sitting position: detection by transesophageal echocardiography. Acta Anaesthesiol Scand 42 643-647.

24. Albin MS, Carroll RG, Maroon JC (1978) Clinical considerations concerning detection of venous air embolism. Neurosurgery 3: 380-384.

25. Domaingue CM (2005) Neurosurgery in the sitting position: a case series Anaesth Intensive Care 33: 332-335.

26. Voorhies RM, Fraser RA, Van Poznak A (1983) Prevention of air embolism with positive end expiratory pressure. Neurosurgery 12: 503-506.

27. Lechat P, Mas JL, Lascault G, Loron P, Theard M, et al. (1988) Prevalence of patent foramen ovale in patients with stroke. N Engl J Med 318: 1148-1152.

28. De Martel T (1908) Un point de technique opératoire dans la craniectomie. Presse Med 16: 641-643.

29. Buckland RW, Manners JM (1976) Venous air embolism during neurosurgery. A comparison of various methods of detection in man. Anaesthesia 31: 633-643.

30. Standefer M, Bay JW, Trusso R (1984) The sitting position in neurosurgery: a retrospective analysis of 488 cases. Neurosurgery 14: 649-658.

31. De Martel T (1931) Surgical treatment of cerebral tumors: technical considerations. Surg Gynecol Obstet 52: 381-385.

32. Gale T, Leslie K (2004) Anaesthesia for neurosurgery in the sitting position. $J$ Clin Neurosci 11: 693-696.

This article was originally published in a special issue, Management of Neurosurgical Complications handled by Editor(s). Dr. Athanasios K. Petridis, Department of Neurosurgery, University of Schleswig Holstein, Germany 